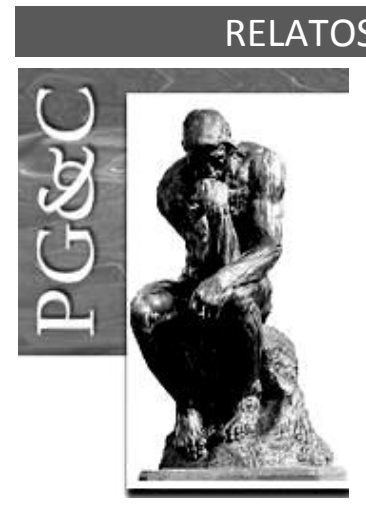

\title{
APLICAÇÃO DOS CONHECIMENTOS ADQUIRIDOS NO MESTRADO NA PRÁTICA PROFISSIONAL: UM ESTUDO DE CASO
}

\author{
Maria Elisângela Fagundes da Silva Viana \\ Mestre em Gestão Pública pela Universidade Federal de Pernambuco, \\ Brasil. Servidora Técnica Administrativa da Universidade Federal de \\ Pernambuco, Brasil. \\ E-mail: mariaelisangela2000@yahoo.com.br \\ Nadi Helena Presser \\ Doutora em Engenharia da Produção pela Universidade Federal de Santa \\ Catarina, Brasil. Professora da Universidade Federal de Pernambuco, \\ Brasil. \\ E-mail: nadihelena@uol.com.br
}

\begin{abstract}
Abinair Bernardes da Silva
Mestre em Ciências Contábeis pela Universidade Federal de Pernambuco, Brasil. Professora da Universidade Federal Rural de Pernambuco, Brasil.

E-mail: abinairbernardes@hotmail.com
\end{abstract}

\begin{abstract}
Resumo
Investiga o grau de aplicabilidade dos conhecimentos adquiridos na produção das dissertações de mestrado profissional da Universidade Federal de Pernambuco para contribuir com demandas específicas da prática profissional. Pesquisa aplicada com coleta de dados realizada por meio de três fontes distintas: as dissertações depositadas no Sistema Integrado de Bibliotecas, desenvolvidas pelos Servidores Técnicos Administrativos em Educação da Universidade Federal de Pernambuco, concluintes em um dos cursos de Mestrado Profissional em Gestão Pública para o Desenvolvimento do Nordeste, Ergonomia, Políticas Públicas e Administração, no período de 2012 a 2016; entrevistas semiestruturadas com os 50 servidores concluintes na categoria de mestres no referido período em um dos cursos acima mencionados, autores das dissertações; e entrevistas semiestruturadas com duas pró-reitoras da PróReitoria de Gestão de Pessoas e Qualidade de Vida da Universidade Federal de Pernambuco. Os resultados evidenciam que, das 92 dissertações analisadas, 79 investigaram temas cujo locus de análise é a própria universidade. Esses resultados evidenciam que os servidores estão interessados em solucionar problemas relativos aos seus setores de atuação e da própria universidade. Todavia, a pesquisa constata que a universidade ainda não definiu políticas organizacionais de incentivo à transferência do conhecimento produzido nas pesquisas, embora os referidos servidores acreditem que esses conhecimentos têm potencial de aplicabilidade e afirmem que eles teriam interesse em aplicar os resultados de suas pesquisas na universidade, caso fosse essa uma política da instituição. Conclui-se que a inserção social dos mestrados profissionais é visivelmente profissional. Carece, no entanto, de uma política de incentivo de transferência e aplicação do conhecimento no âmbito organizacional.
\end{abstract}

Palavras-chave: Mestrado profissional. Transferência e aplicação do conhecimento. Universidade Federal de Pernambuco. 


\title{
KNOWLEDGE APPLICATION OF THE RESULTS OF THE MASTER'S DEGREE DISSERTATIONS IN THE PROFESSIONAL PRACTICE: \\ A CASE STUDY
}

\begin{abstract}
This paper researches the degree of knowledge application of master's degree dissertations of the Federal University of Pernambuco on specific professional needs. It is an applied research that collects data from three different sources: master's degree dissertations of the Administrative and Technical employees on Education of the Federal University of Pernambuco, graduated from one of the three Professional Master Degree courses in Public Management for Northeast Development (Ergonomics, Public Policies, Administration), during 2012-2016 period, and available at the Integrated System of Libraries; semi-structured intervie ws with 50 master degree graduates in that period in one of the above mentioned courses; and semi-structured interviews with two pro-rectors of the Office of People Management and Quality of Life at the Federal University of Pernambuco. Results show that 79 out of 92 dissertations researched subjects whose locus of analysis was the university itself. It shows that employees are interested in solving problems related to their professional activity in the university. However, results also indicate the university has not yet defined organizational policies encouraging knowledge transfer, although employees believe their research results have potential applicability and affirm, they would be interested in applying them in the university if there was an explicit institutional policy. It is concluded that the social insertion of professional master's degree courses is notably professional, however, the university lacks a policy encouraging knowledge transfer and applica tion of research results.
\end{abstract}

Keywords: Professional Master's Degree courses. Knowledge transfer and application. Federal University of Pernambuco.

\section{INTRODUÇÃO}

Questões relacionadas ao conhecimento organizacional, visando mais eficiência e eficácia na oferta de produtos, serviços e nos processos para executá-los, têm surgido como um importante campo de pesquisa (NONAKA; TAKEUCHI, 1997, 2001; BHATT, 2001; GARCIA; SILVA, 2015). Além disso, alguns pesquisadores assinalam a absorção, a transferência e a aplicação do conhecimento como os maiores desafios dos gestores organizacionais (JONES; LEONARD, 2009; SALAS et al., 2012; BATISTA, 2012; HEIDEN et al. 2015; CEPEDA-CARRION et al., 2017).

Batista (2012) pressupõe que as pessoas desempenhem papéis importantes na produção e apropriação do conhecimento nas organizações públicas e privadas. Segundo esse autor, isso justifica muitos dos investimentos em programas de educação e capacitação visando incrementar a habilidade das pessoas de criar e aplicar conhecimento e, assim, melhorar o desempenho organizacional. "O conhecimento agrega valor apenas quando é aplicado nos processos de apoio, processos finalísticos e, consequentemente, melhora produtos e serviços da organização pública." (BATISTA, 2012, p. 64).

Organizações governamentais e privadas têm enfrentado desafios, porém também identificado oportunidades, muitas das quais com importantes implicações para o desenvolvimento das pessoas. Em razão disso, pesquisadores como Sitzmann et al. (2009), Salas et al. (2012), García et al. (2014) e Heiden et al. (2015) têm assumido a tarefa de entender como, em uma sociedade do conhecimento, a gestão de recursos humanos pode desempenhar um papel mais ativo, que signifique mais efetividade da área em termos de agregação de resultados para as organizações.

Perspectivas em Gestão \& Conhecimento, João Pessoa, v. 8, n. 3, p. 179-191, set./dez. 2018. 
O que mais se lê nesses autores é que agregar resultados nas organizações se efetiva no processo de gestão do conhecimento que pressupõe criar condições para a aquisição, transferência e aplicação do conhecimento humano, pois, a premissa desses pesquisadores é que os resultados organizacionais se baseiam, em grande medida, nas capacidades e atitudes das pessoas, os colaboradores. Mas, por outro lado, a gestão do conhecimento, segundo os mesmos autores, depende de arranjos organizacionais, viabilizados e amparados pelos líderes e gestores das organizações. Os pesquisadores agora reconhecem que vários níveis dentro de uma organização (nível em âmbito do indivíduo, da equipe ou da própria organização) influenciam e são afetados pela gestão do conhecimento organizacional (HEIDEN et al., 2015; CEPEDA-CARRION et al., 2017).

Com base no exposto, esta pesquisa investigou o grau de aplicabilidade dos conhecimentos adquiridos na realização das dissertações de mestrado para contribuir com demandas específicas da prática profissional dos concluintes dos cursos de mestrado profissional. Especificamente, este estudo iniciou caracterizando as dissertações em relação ao lócus de análise; identificou se houve aplicação do conhecimento adquirido na solução das questões de pesquisa estudadas na dissertação e os fatores que teriam interferido positiva ou negativamente no processo, segundo as percepções dos concluintes; e averiguou a disposição dos concluintes em desenvolver uma temática de pesquisa com potencial de aplicação na Universidade Federal de Pernambuco (UFPE).

Para fins desta pesquisa, aplicar o conhecimento adquirido no desenvolvimento das dissertações de mestrado é a capacidade de colocar em ação os produtos da pesquisa: as descobertas empíricas e teóricas. A utilização do conhecimento significa, primeiro, sua absorção, transferência, circulação no âmbito da universidade e sua apropriação entre as pessoas. O conhecimento científico eticamente gerado, tendo por meta a melhoria da qualidade de vida de todos os servidores públicos e dos cidadãos, precisa também ser usado com igual cuidado e rigor. O que significa ser orientado para resolver problemas efetivos, e não somente se traduzir num trabalho acadêmico necessário para obter o diploma do curso. Isso caracteriza a contribuição prática desta pesquisa.

Entretanto, o conhecimento em si não é suficiente para garantir o seu uso. Para que o conhecimento adquirido alcance sua relevância social e atenda às necessidades organizacionais é preciso que haja um compromisso tanto dos pesquisadores como dos gestores públicos. Dos pesquisadores, no sentido de transformar esse conhecimento em aplicações práticas e úteis para a sociedade; dos gestores públicos, bem como das instituições financiadoras, no sentido de planejar e avaliar a formulação de programas de qualificação e capacitação e ampliar o diálogo com os pesquisadores para operar o uso social do conhecimento produzido (MARTELETO, 2009).

Considerando que os Servidores Técnicos Administrativos em Educação (TAEs) participantes dos mestrados profissionais na UFPE são profissionais, e que os temas abordados em suas pesquisas investigaram soluções para problemas reais da própria universidade, a contribuição social desta pesquisa está na reflexão sobre a possibilidade de a UFPE aplicar esses conhecimentos produzidos. A aplicação do conhecimento adquirido a partir dos processos de formação destes servidores ampliaria a aceitabilidade do processo e justificaria ainda mais os investimentos realizados.

A UFPE implantou e mantém políticas de capacitação e qualificação para os servidores, amparada nas legislações vigentes, por meio da Pró-Reitoria de Gestão de Pessoas e Qualidade de Vida (PROGEPE), que instituiu a política de capacitação e qualificação, com base nos seguintes dispositivos legais:

a. Resolução no 9/2006/UFPE, que institui Programa de Capacitação e Qualificação para servidores técnico-administrativos em educação; 
b. Lei no 11.091/2005, que institui o Plano de Carreira dos Cargos TécnicoAdministrativos em Educação (PCCTAE), e alterações introduzidas pela Lei no 12.772/12;

c. Decreto no 5.707/06, que institui a Política e Diretrizes para o desenvolvimento de pessoal da administração pública federal direta, autárquica e fundacional;

d. Decreto no 5.825/06, que estabelece as diretrizes para elaboração do Plano de Desenvolvimento dos Integrantes do PCCTAE.

Nesse contexto, esta pesquisa contribuiu nas instâncias institucional e social, uma vez que poderá servir como fonte de informações para o processo de monitoramento das políticas de ações em recursos humanos, além de estimular pesquisas futuras.

\section{ABSORÇÃO, TRANSFERÊNCIA E PLICAÇÃO DO CONHECIMENTO NA ADMINISTRAÇÃO PÚBLICA}

Segundo Heiden et al. (2015), treinar visa gerar mudanças de habilidades e destreza e um programa de educação gera conhecimentos. Logo, ambos, educação e treinamento, são recursos para assimilar, adquirir e aplicar conhecimentos. Todavia, a educação compreende o processo pelo qual uma pessoa desenvolve um entendimento sobre um assunto, de maneira que possa formar opinião independente, estabelecer prioridades, discutir e entender uma metodologia, utilizar e aplicar técnicas adequadas. Por outro lado, o objetivo do treinamento é ensinar uma pessoa a realizar tarefas específicas com base em uma metodologia aceita. Em outras palavras, é a capacidade de usar técnicas conhecidas e disponíveis.

Absorver novos conhecimentos é a capacidade de identificar, assimilar e explorar o conhecimento para promover inovação ou aperfeiçoar a prestação do serviço público à sociedade (COHEN; LEVINTHAL, 1990). Embora possa haver várias maneiras de obter novos conhecimentos, Heiden et al. (2015) evidenciam a capacidade de absorção como um aspecto do processo de aprender. Para eles, a capacidade de absorção se refere a um recurso interno que fortalece a habilidade organizacional de entender, assimilar, para, posteriormente, aplicar novos conhecimentos. Assim, a aquisição de um novo conhecimento é produto da capacidade organizacional, habilitando-a a reconhecer e sintetizar adequadamente fontes externas e internas de novos conhecimentos. A capacidade de absorção do conhecimento refere-se, assim, à criação de novos conhecimentos ou à substituição do existente.

Portanto, o papel da educação e do treinamento constitui, nas considerações de Heiden et al. (2015), o principal determinante da criação do conhecimento individual e organizacional, mas mostra também uma grande correlação com a capacidade de absorção de uma pessoa ou de uma organização.

Lim (2009) cita a distinção de três tipos de capacidade de absorção: a) disciplinar aquisição de conhecimento científico e sua conversão em formas úteis para resolver problemas práticos; b) específico de domínio - a habilidade do conhecimento adquirido diretamente, relacionado à resolução de problemas para produzir inovações comerciais; c) codificado - a capacidade de uma organização de absorver conhecimento incorporado em ferramentas, artefatos e processos.

Educação é parte do capital humano, pois o investimento melhora diretamente os níveis de produção econômica de um país, e as habilidades dos recursos humanos, como enfatizado por Lai, Peng e Bao (2006). Levando em consideração o crescimento econômico chinês, esses autores argumentam que o investimento em capital humano promove indiretamente o crescimento econômico, em função dos investimentos em pesquisa e desenvolvimento, potencializando a capacidade de absorção. Os autores afirmam que a taxa de retorno sobre o capital humano é acentuada, provocando inclusive um crescimento sustentável.

Perspectivas em Gestão \& Conhecimento, João Pessoa, v. 8, n. 3, p. 179-191, set./dez. 2018. 
Murovec e Prodan (2009) distinguem duas dimensões da capacidade de absorção: a) capacidade de absorção impulsionada pela ciência, fundamentada na informação científica proveniente de pesquisas nas universidades, institutos de pesquisa e afins; $b$ ) capacidade de absorção puxada pela demanda, fundamentada nas informações de mercado referentes aos clientes, competidores e fornecedores, entre outros.

A transferência de conhecimento, por seu turno, segundo Cepeda-Carrion et al. (2017), envolve essencialmente $o$ ato de tornar o conhecimento disponível para outros dentro da organização. No entanto, segundo esses autores, o processo de transferência de conhecimento sofre muitos obstáculos motivacionais e organizacionais. Por exemplo, os funcionários podem resistir aos novos conhecimentos de outros grupos, departamentos ou seções, porque não estão relacionados ao seu conhecimento prévio.

Tratando exclusivamente do processo de treinamento, Salas et al. (2012) ressaltam a importância de como as atividades antes, durante e após o treinamento influenciam a sua eficácia. Na fase do pré-treinamento é importante considerar características situacionais e individuais, isto é, o modo como o treinamento é planejado em conjunto com as habilidades do indivíduo, ou como experiências anteriores podem influenciar os resultados.

E um exemplo de um avanço teórico na área de treinamentos, segundo Salas et al. (2012), diz respeito à transferência do conhecimento. A transferência refere-se à medida em que a aprendizagem durante o treinamento é, posteriormente, aplicada no trabalho ou afeta o desempenho no trabalho. Assim, a transferência do treinamento pode ser estimada por uma correlação entre os escores de aprendizagem em treinamento e métricas de desempenho no trabalho. A transferência é fundamental porque, sem ela, é menos provável que uma organização receba benefícios tangíveis de seus investimentos em treinamento.

García et al. (2014) chamam atenção para o fato de que a política de qualificação e desenvolvimento de pessoas tem sido muitas vezes objeto de crítica por ser muito dispendiosa e porque não consegue transferir o conhecimento adquirido para o trabalho. Por essa razão, o os programas de capacitação e treinamento de pessoas geralmente são vistos como um centro de custos que precisa ser controlado ou mesmo removido quando as organizações estão passando por tempos difíceis.

$\mathrm{Na}$ verdade, os programas às vezes são implementados por razões diferentes da melhoria do desempenho, sublinham García et al. (2014), mas por outros motivos, tais como: conformidade legal, recompensar funcionários, manter trabalhadores mais bem qualificados. Ou simplesmente há subsídios governamentais para desenvolver atividades relacionadas à qualificação.

A existência de um certo grau de coesão sobre a conexão entre a política de treinamento e o desempenho organizacional não parece lógica em tais circunstâncias. Assim, a maioria das organizações apenas avalia programas de treinamento com critérios ligados à reação e às percepções dos participantes sobre os programas dos quais eles participam e muito poucas delas medem o impacto que a educação e o treinamento causam no ambiente e no desempenho do trabalho (GARCÍA et al., 2014).

Um estudo de Kontoghiorghes (2004) constatou que a transferência das habilidades adquiridas e do conhecimento construído para o ambiente de trabalho é facilitada por um clima favorável e em consequência de outros aspectos do ambiente de trabalho. Entre esses outros aspectos destacam-se, especificamente, ambientes caracterizados por alto envolvimento entre colegas e compartilhamento de informações, autonomia das tarefas ou compromisso organizacional com a qualidade.

Pesquisadores investigaram vários facilitadores de transferência de conhecimento. Entre esses facilitadores, Cepeda-Carrion et al. (2017) incluem o capital social. A transferência de conhecimento, bem como o intercâmbio recíproco de conhecimento organizacional incluem dois agentes ou componentes: uma fonte e um destinatário.

Perspectivas em Gestão \& Conhecimento, João Pessoa, v. 8, n. 3, p. 179-191, set./dez. 2018. 
A teoria do capital social apresentada por Cepeda-Carrion et al. (2017) sugere que as relações sociais estimulam e facilitam as atividades de conhecimento da fonte e do destinatário. Do ponto de vista de uma realidade de conhecimento, boas relações sociais entre funcionários podem aumentar a confiança, facilitando a transferência de conhecimento. Do ponto de vista do beneficiário, boas relações sociais com colegas de trabalho facilitam o acesso a conhecimentos diferentes e variados. No entanto, os destinatários que não possuem conhecimentos associados anteriores podem ter problemas para aprender o conhecimento da fonte e lutar para aceitá-lo. "Essa falta de conhecimento prévio e a resistência à aprendizagem de novos conhecimentos levará a uma baixa capacidade de absorção." (KANG; HAU, 2014, p. 759).

\subsection{A aplicação do conhecimento}

A aplicação do conhecimento é sublinhada por Cepeda-Carrion et al. (2017) como um processo particularmente complexo, cujo fim está conectado ao início. Assim, os mecanismos de absorção e transferência são essenciais para aplicar o conhecimento. Portanto, se uma universidade ou qualquer outra organização deseja capitalizar o conhecimento que possui, a mesma deve entender como o conhecimento é criado, absovido, transferido e aplicado. Como esses processos não constituem uma sequência linear, todos ou apenas alguns deles podem requerer mais atenção.

Bhatt (2001) ressalta que aplicar o conhecimento significa tornar o conhecimento mais ativo e relevante na criação de valores para a organização. Os critérios de avaliação da utilidade do conhecimento não são facilmente evidentes. No entanto, se uma organização acredita na utilidade do conhecimento, irá apoiar suas atividades práticas e cotidianas.

Nedjat et al. (2014) usam o termo "tradução do conhecimento" e o definem como um processo que inclui síntese, disseminação, troca e aplicação de conhecimento. Segundo esses autores, em mais de uma década, foram tomadas algumas medidas para fortalecer a tomada de decisões baseada em evidências e na tradução do conhecimento no Irã.

Aqui, é importante destacar a menção de alguns autores (TEECE et al., 1997; ANDREEVA; CHAIKA, 2006; TEECE, 2007; CEPEDA-CARRION et al. 2017), sobre a importância de as organizações potencializarem as suas capacidades dinâmicas, desenvolvidas praticamente por meio do conhecimento acumulado ao longo dos anos. Teece et al. (1997) foram os primeiros a cunhar o conceito de capacidades dinâmicas e o definiram como a aptidão de uma organização de integrar, construir e reconfigurar competências internas e externas para lidar com ambientes em rápida mudança, ou com ambientes muito complexos. Dito de outro modo, é a capacidade de uma organização de criar, estender ou modificar sua base de recursos, propositadamente (ANDREEVA; CHAIKA, 2006).

Cepeda-Carrion et al. (2017) veem a abordagem das capacidades dinâmicas em estreita relação com a criação e aplicação do conhecimento organizacional. Daí a importância de compartilhar e aplicar esse conhecimento, criando dentro da organização um ambiente propício para valorizar o conhecimento como um ativo.

Teece (2007) ressalta que as organizações necessitam criar uma base subjacente às capacidades dinâmicas (microfoundations), tipo um conjunto de tarefas denominadas de percepção, assimilação, reconfiguração (sensing, seizing, reconfiguring). Isto é, identificar novas oportunidades, apreendê-las e adotá-las, configurando-as de uma nova forma na organização. A Figura 1 representa graficamente a sequência de atividades ou tarefas que devem ser realizadas dentro da organização, visando criar as bases das capacidades dinâmicas.

Primeiro, conforme Teece (2007), as organizações precisam se concentrar nas atividades de percepção (sensing), para descobrir oportunidades latentes e novas. Para fazer isso, os gerentes podem identificar informações relevantes sobre as quais concentrem sua

Perspectivas em Gestão \& Conhecimento, João Pessoa, v. 8, n. 3, p. 179-191, set./dez. 2018. 
atenção, no âmbito interno e externo da organização. Essa terá que ser uma atividade intencional e sistemática, não deixando questões ao acaso.

Figura 1 - Sequência das bases das capacidades dinâmicas

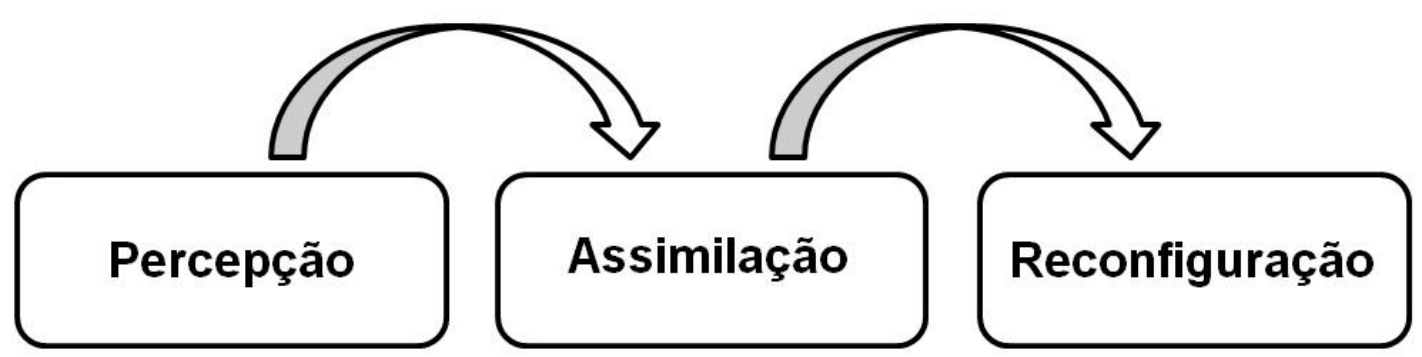

Fonte: Cepeda-Carrion et al. (2017) adaptado de Teece (2007)

Quando uma nova oportunidade for detectada, o próximo passo, segundo Teece (2007), é avaliar a oportunidade e assimilá-la (seizing). Isso pressupõe analisar sua exiquibilidade, aderência ao modelo de negócio, analisar as necessidades de recursos e tomar decisões para investir em tecnologia ou outros recursos fundamentais, além de analisar quais mudanças serão essenciais.

Depois a reconfiguração (reconfiguring) de recursos torna-se básica, observa Teece (2007). A reconfiguração envolve a realocação de recursos, uma vez que a nova combinação aumenta o valor da organização. Esta reconfiguração possibilita à organização se adaptar às mudanças no ambiente, descartar rotinas obsoletas e alcançar resultados maiores e sustentáveis.

Cepeda-Carrion et al. (2017) constatam que o processo de gestão do conhecimento tem sido um tópico amplamente examinado na literatura por muitos anos. Durante muito tempo, as organizações queriam "saber o que sabiam", ou seja, trazer para o nível consciente o que elas sabiam fazer, mas que até certo ponto nunca haviam parado para analisar. Além disso, as organizações pretendiam ir além, almejavam saber como eram capazes de fazer o melhor uso do conhecimento que possuíam.

No modelo de pesquisa proposto por Cepeda-Carrion et al. (2017) (ver Figura 2), os referidos autores mostram como a combinação do processo de gestão do conhecimento constitui uma capacidade dinâmica e como essa combinação conduz à criação de valor para o cliente. Este modelo reconhece o conhecimento como o recurso estratégico mais importante. A partir dessa abordagem, o modelo se concentra na relevância de diferentes processos que permitem a criação, intercâmbio e uso do conhecimento e a inter-relação com as bases das capacidades dinâmicas (percepção, assimilação, reconfiguração). Igualmente, o modelo sugere como esses processos combinados geram valor superior para o cliente, e tudo isso para alcançar um desempenho superior. 
Figura 2 - Modelo proposto de integração das capacidades dinâmicas com a gestão do conhecimento

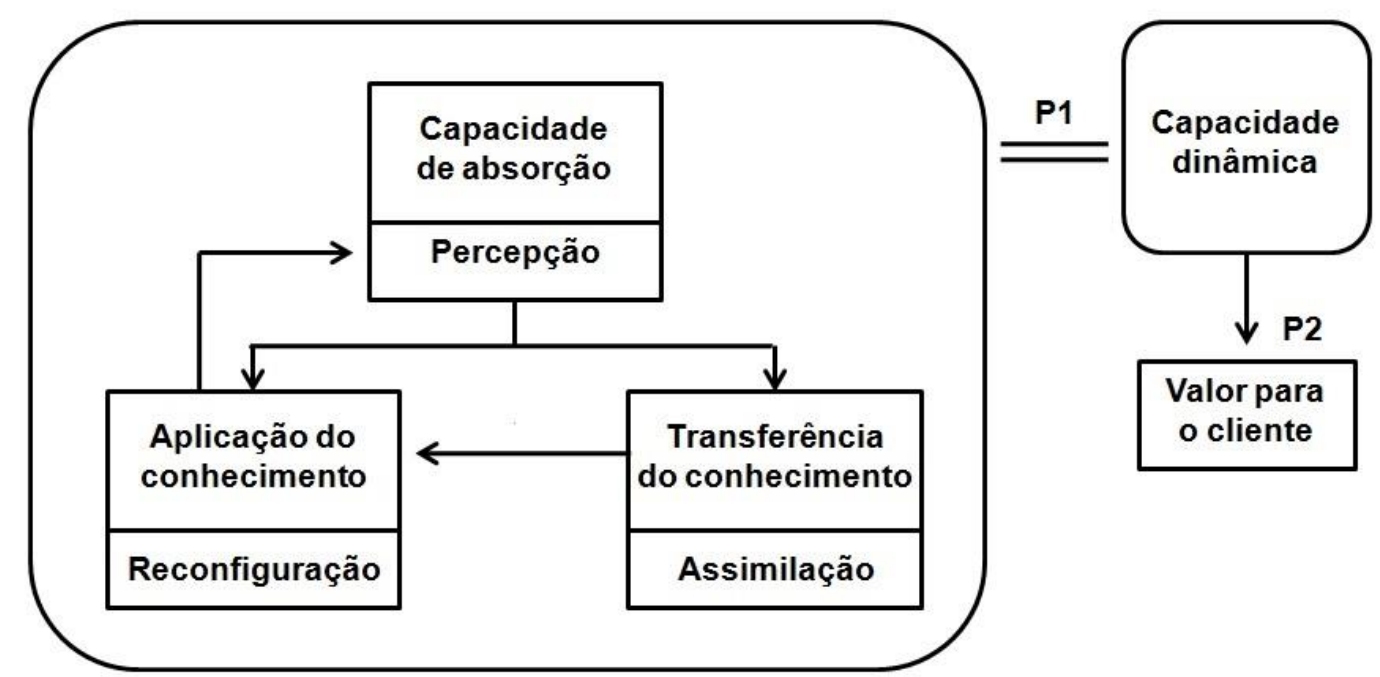

Fonte: Cepeda-Carrion et al. (2017)

Cepeda-Carrion et al. (2017) lembram que o conhecimento é adquirido para ser aplicado. Portanto, é essencial que esse conhecimento chegue à organização, para que seu compartilhamento ocorra por meio do processo de transferência de conhecimento. Todavia, sem a aplicação do conhecimento, os processos anteriores têm pouco propósito.

\subsection{Pós-graduação stricto sensu e os mestrados profissionais}

A Portaria 080 de 16 de dezembro de 1998 (CAPES, 1998) que dispõe sobre o reconhecimento dos mestrados profissionais é um fenômeno relativamente recente na pósgraduação brasileira. Mas, é na Portaria Normativa No. 17 de 28 de dezembro de 2009 (CAPES, 2009) que os objetivos do mestrado profissional são delimitados (CAPES, 2009).

Entre seus vários objetivos, o que se lê na referida portaria é que o mestrado profissional visa capacitar profissionais qualificando-os para o exercício da prática profissional, transferir conhecimento para a sociedade e promover a articulação integrada da formação profissional com entidades demandantes de naturezas diversas, visando melhorar a eficácia e a eficiência das organizações públicas e privadas por meio da solução de problemas de geração e aplicação de processos de inovação apropriados.

O que se lê na referida portaria, é que o mestrado profissional atende a uma necessidade de profissionais que atuam no mercado e necessitam de qualificação. Por mercado inclui-se não apenas as empresas privadas, mas, também, as públicas e as organizações do terceiro setor. Ressalta-se, ainda, que o mestrado profissional também focaliza no desenvolvimento da competência para a pesquisa, mas, prioritariamente, de natureza aplicada.

Mesmo após quase 20 anos do reconhecimento dessa modalidade profissional para a pós-graduação stricto sensu em nível de mestrado, ainda há muitas dúvidas sobre essa formação acadêmica. Uma característica que se tornou quase senso comum no Brasil e por isso gera dúvidas em relação ao mestrado profissional, é a ideia construída de que "[...] a teoria pura seria destinada aos pesquisadores puros da Academia." (RIBEIRO, 2010, p. 447). Este autor contesta o grau de pureza dessa teoria e dessa Academia e a validade da pureza para a criação, ou movimentação da teoria e questiona: "Por que um mestrando profissional, com toda sua inserção social, não pode também produzir teoria?" (RIBEIRO, 2010, p. 447).

Perspectivas em Gestão \& Conhecimento, João Pessoa, v. 8, n. 3, p. 179-191, set./dez. 2018. 
Seguindo nessa mesma perspectiva, as análises de Volpato (2013) em relação à ciência apontam que as dúvidas relativas às diferenças entre mestrado profissional e acadêmico ocorrem porque esta concepção se baseia no produto final da ciência e não no mecanismo de gerar conhecimento. Sendo a ciência uma estratégia de gerar conhecimento e interpretar o mundo, o produto desse conhecimento pode ser aplicado imediatamente ou pode não apresentar uma aplicação prática imediata. Volpato $(2013$, p. 101) sublinha que "a diferença entre o conhecimento básico e o aplicado não está na forma de construção (ciência), mas na sua correspondência social: serve para agora ou não." (VOLPATO, 2013, p. 101).

Portanto, nas reflexões de Volpato (2013, p. 101), a dicotomia entre ciência básica e ciência aplicada "[...] é infundada e produto de interpretações equivocadas do que seja ciência.". Ou seja, do modo como essa dicotomia é colocada, presume-se que existem duas ciências e, por extensão, duas maneiras científicas de se construir conhecimento: a básica e a aplicada.

Ribeiro (2010) se fundamenta na noção dos usos sociais da ciência de Bourdieu (2003) para contribuir para o debate a respeito da consolidação do mestrado profissional no Brasil. Nas suas análises, a distinção entre o que Bourdieu chama de ciências "puras", que seriam autônomas, e de ciências "aplicadas", heterônomas, "guarda uma forte relação entre a separação que se constrói entre os mestrados ditos acadêmicos e aqueles ditos profissionais." (RIBEIRO, 2010, p. 435).

O confronto de visões antagonistas que opõe a autonomia dos pesquisadores ditos "puros" à heteronomia dos pesquisadores "aplicados" impede de ver que aquilo que se confronta; na realidade, são duas formas, ambas relativamente autônomas de pesquisa, uma voltada, antes, pelo menos na intenção, para a invenção científica e participante (bem ou mal) da lógica do campo científico, a outra voltada, antes, para a inovação, mas igualmente independente, para o melhor e para o pior, das sanções do mercado e capazes de designar, para si própria, fins igualmente universais de serviço público e de promoção do interesse geral. (BOURDIEU, 2003, p. 58 apud RIBEIRO, 2010, p. $434-435)$.

Seja qual for o enfoque de uma pesquisa, o importante, segundo Ribeiro (2010), é que se construa conhecimento de bom nível. Nesta perspectiva, pode-se assumir que no caso das pesquisas ditas aplicadas dos mestrados profissionais, há uma intencionalidade explícita da pesquisa, pois expressa um caráter político e social do problema ao qual se pretende solucionar.

Assim, nas análises Ribeiro (2010), não se está lançando necessariamente os mestres profissionais na ideologia de mercado, nem tampouco fechando as portas para diversos debates dentro desses cursos sobre modos de melhoria, por meio de pesquisas científicas, de inúmeras relações sociais produtivas e reprodutivas, não necessariamente mercantis ou privadas. Pelo contrário, a própria regulamentação dos mestrados profissionais diverge dessa acepção ao permitir que esses mestres possam lecionar em universidades e, inclusive, candidatar-se a doutorados, formando-se, em longo prazo, como pesquisadores.

Além do mais, há de se ressaltar os objetivos da criação dos mestrados profissionais. A Portaria Normativa No. 17 de 28 de dezembro de 2009 (CAPES, 2009) que dispõe sobre 0 mestrado profissional no âmbito da Fundação Coordenação de Aperfeiçoamento de Pessoal de Nível Superior (CAPES), no seu Art. 2으, especifica que essa modalidade de pós-graduação stricto sensu visa a formação de profissionais qualificados pela apropriação e aplicação do conhecimento embasado no rigor metodológico e nos fundamentos científicos. 


\section{PROCEDIMENTOS METODOLÓGICOS}

Para a classificação deste estudo de caso realizado na UFPE, tomou-se como base a categorização apresentada por Vergara (2000): quanto à abordagem, quanto aos fins e aos meios e quanto ao procedimento técnico de coleta dos dados e evidências.

A pesquisa gerou conhecimentos que contribuem com questões gerenciais relacionadas à formação dos recursos humanos, embora, mais do que trazer respostas, levantou questões que precisam ser discutidas no âmbito das universidades, configurando-se como pesquisa exploratória. Os dados foram quantificados, organizados e sumarizados visando à sua interpretação, assumindo, assim, uma abordagem quantitativa (MARTINS; THEÓPHILO, 2009). Os dados foram filtrados, organizados, tabulados e submetidos a procedimentos estatísticos, facilitando sua interpretação.

Quanto aos meios, na sua peculiaridade de pesquisa descritiva, delinearam-se as características de um grupo (os TAEs) e dos cursos de mestrado profissional, principalmente naquilo que se refere à aplicação do conhecimento adquirido no desenvolvimento das suas dissertações de mestrado profissional. A coleta de dados foi realizada por meio de três fontes distintas: as dissertações depositadas no SIB, desenvolvidas pelos TAEs da UFPE, concluintes em um dos cursos de Mestrado Profissional em Gestão Pública, Ergonomia, Políticas Públicas e Administração, no período de 2012 a 2016; aplicação de questionários semiestruturados com os TAEs concluintes dos mestrados e autores das dissertações depositadas no SIB; e entrevistas semiestruturadas com duas Pró-Reitoras da PROGEPE.

Como critério para a seleção das dissertações de mestrado, optou-se por aquelas que foram depositadas no SIB, local onde as produções acadêmicas e científicas da UFPE são armazenadas, preservadas e publicadas. Embora uma dissertação já tenha sido defendida e aprovada, ela somente é depositada no SIB após atender todos as recomendações que a banca pode solicitar durante ao exame de defesa. Por esse motivo, somente foram objeto desta pesquisa aquelas que foram depositadas. O total de dissertações analisadas foi de 92 documentos, distribuídos entre os diferentes cursos (Ver Tabela 1).

Tabela 1 - Total de dissertações depositadas no período de 2012 a 2016

\begin{tabular}{lccc}
\hline Programa & $\begin{array}{l}\text { Dissertações } \\
\text { defendidas }\end{array}$ & $\begin{array}{l}\text { Dissertações } \\
\text { depositadas }\end{array}$ & Porcentagem \\
Políticas Públicas & 10 & 5 & $50 \%$ \\
Ergonomia & 18 & 17 & $94 \%$ \\
Administração & 26 & 23 & $88 \%$ \\
Gestão Pública & 63 & 47 & $75 \%$ \\
Total & $\mathbf{1 1 7}$ & $\mathbf{9 2}$ & $\mathbf{7 9 \%}$ \\
\hline
\end{tabular}

Fonte: Dados da pesquisa (2018)

O questionário aplicado foi elaborado no Google Docs, estruturado com perguntas relacionadas aos objetivos da pesquisa. Inicialmente foi realizado um pré-teste com dois concluintes de cada curso. A aplicação do questionário ocorreu no mês de novembro de 2017. A Tabela 2 apresenta a quantidade de questionários aplicados e o total de respondentes por programa de mestrado. $O$ total de respondes foi de $50 \mathrm{TAEs}$, representando $54 \%$ do total dos 92 concluintes. 
Tabela 2 - Respondentes do questionário

\begin{tabular}{lccc}
\hline Programa & $\begin{array}{c}\text { No questionários } \\
\text { aplicados aos TAES }\end{array}$ & $\begin{array}{c}\text { No total de respostas } \\
\text { recebidas }\end{array}$ & Porcentagem \\
Políticas Públicas & 5 & 4 & $80 \%$ \\
Ergonomia & 17 & 7 & $41 \%$ \\
MPA & 23 & 10 & $43 \%$ \\
MGP & 47 & 29 & $62 \%$ \\
Total & $\mathbf{9 2}$ & $\mathbf{5 0}$ & $\mathbf{5 4 \%}$ \\
\hline
\end{tabular}

Fonte: Dados da pesquisa (2018)

Para caracterizar as dissertações, os dados recuperados do SIB e disponibilizados em planilhas Excel foram exportados para o software VantagePoint, onde foram reformatados visando à uniformização dos campos, tais como nomes dos orientadores, loci da pesquisa e dados de temporalidade (ano de defesa). Posteriormente, foram submetidos a contagem em formato de lista de distribuição e relacionados em formato de matrizes. As listas de distribuição foram exportadas para o programa Excel e com esses registros estatísticos foram geradas tabelas, gráficos, e identificados os loci de pesquisa.

Para a análise dos questionários foram seguidas as etapas de classificação dos dados, tabulação e análise estatística. Para a análise estatística dos questionários utilizou-se da análise descritiva e da relação das variáveis, ambas operacionalizadas por meio do software Statistical Package for the Social Sciences (SPSS).

As entrevistas com as duas Pró-Reitoras da PROGEPE que atuaram no cargo no período de 2012 a 2016 tiveram como objetivo entender se havia uma política de monitoramento e avaliação dos TAEs participantes dos cursos de mestrado profissional antes, durante e após o processo de qualificação. As entrevistas foram realizadas nos dias 23/02/2018 e 09/03/2018. A PROGEPE é responsável pelo planejamento, execução e avaliação das ações de administração e desenvolvimento de recursos humanos, e, assim, as entrevistadas estavam diretamente envolvidas na participação dos TAEs nos referidos cursos de mestrado profissional.

\section{RESULTADOS E DISCUSSÃO}

A seguir, a apresentação dos dados mostra as respostas das três fontes de coleta de dados. A ênfase, contudo, está na apresentação dos resultados dos questionários aplicados aos TAEs e de suas análises, fazendo relação às questões do instrumento de coleta de dados.

\subsection{Absorção e transferência dos conhecimentos produzidos nas pesquisas}

A caracterização das dissertações desenvolvidas pelos TAEs evidencia um compromisso destes profissionais no intuito de construir conhecimento e solucionar problemas a respeito de seus setores de atuação, com questões relativas ao seu ambiente de trabalho e à própria universidade. As dissertações analisadas revelam a participação hegemônica do locus UPFE: das 92 dissertações analisadas, 79 investigaram temas cujo locus de análise era a própria universidade.

Todavia, uma constatação deste estudo é que transferir o conhecimento produzido nas pesquisas para o interior da UFPE é um processo ainda incipiente. Em uma leitura na Tabela 3 (relativa à questão: Sua chefia imediata solicitou que seu trabalho de dissertação trouxesse alguma contribuição para melhorar o funcionamento do setor (antes, durante ou após conclusão do mestrado)?) nota-se que, do total de 50 respondentes, apenas cinco (10\%) 
afirmaram que a chefia solicitou alguma resposta ou contribuição para o setor de atuação do TAE.

Tabela 3 - Solicitação da chefia referente à contribuição da pesquisa

\begin{tabular}{lccc}
\hline $\begin{array}{c}\text { Contribuição da } \\
\text { pesquisa }\end{array}$ & Frequência & Porcentagem & $\begin{array}{c}\text { Porcentagem } \\
\text { acumulativa }\end{array}$ \\
Não & 45 & 90,0 & 90,0 \\
Sim & 5 & 10,0 & 100,0 \\
Total & 50 & 100,0 & \\
\hline
\end{tabular}

Fonte: Dados da pesquisa (2018)

Em consequência disso, apenas três (6\%) dos TAEs transferiram formalmente o conhecimento no interior da universidade. Os demais encontraram outras iniciativas próprias, como se lê na Tabela 4, a qual apresenta os resultados da questão: Caso algum conhecimento construído em sua dissertação tenha sido aplicado, como foi repassado às pessoas que o utilizam?

Tabela 4 - Transferência do conhecimento

\begin{tabular}{lccc}
\hline \multicolumn{1}{c}{ Modo de transferência } & Frequência & Porcentagem & $\begin{array}{c}\text { Porcentagem } \\
\text { acumulativa }\end{array}$ \\
Outros & 23 & 46,0 & 46,0 \\
Informal, durante expediente do trabalho & 18 & 36,0 & 82,0 \\
Informal, fora do expediente & 6 & 12,0 & 94,0 \\
Formalmente por treinamento & 3 & 6,0 & 100,0 \\
Total & 50 & 100,0 & \\
\hline
\end{tabular}

Fonte: Dados da pesquisa (2018)

Esses resultados corroboram com Jones e Leonard (2009) e Bhatt (2001), que também haviam concluído que, enquanto adquirir conhecimento ainda pode ser uma escolha isolada e individual das pessoas, transferir, por seu turno, requer envolvimento dos líderes e a definição de políticas organizacionais de incentivo à transferência do conhecimento. Isso pressupõe a criação de um clima de confiança, pois duas condições mínimas são necessárias para que ocorra uma efetiva transferência de conhecimento: o transferidor precisa estar disposto a transferir e o receptor precisa ter condições de absorver o conhecimento transferido. Isto é, somente com a absorção do conhecimento e o seu domínio pelo receptor, o processo de transferência se completa (JONES; LEONARD, 2009).

\subsection{Aplicação dos conhecimentos produzidos nas pesquisas}

A aplicação do conhecimento é um processo particularmente relevante, uma vez que a base das vantagens organizacionais (ou competitivas) não reside no próprio conhecimento, mas na sua aplicação (CEPEDA-CARRION et al., 2017). No entanto, o que se lê na Tabela 5 é que, dos 50 respondentes, 23 (46\%) declararam que o conhecimento produzido nas pesquisas de mestrado não foi aplicado na prática administrativa da universidade. 
Tabela 5 - Aplicação dos conhecimentos produzidos na pesquisa

\begin{tabular}{lccc}
\hline Houve & Frequência & Porcentagem & $\begin{array}{c}\text { Porcentagem } \\
\text { acumulativa }\end{array}$ \\
Aplicação & 23 & 46,0 & 46,0 \\
Não & 14 & 28,0 & 74,0 \\
Em parte & 13 & 26,0 & 100,0 \\
Sim & 50 & 100,0 & \\
Total & &
\end{tabular}

Fonte: Dados da pesquisa (2018)

Em seguida, outra questão do questionário buscou identificar os motivos da não aplicação do conhecimento ou da aplicação em parte, cuja resposta é apresentada na Tabela 6.

Tabela 6 - Os motivos da não aplicação do conhecimento produzido nas pesquisas

\begin{tabular}{lcccc}
\hline \multicolumn{1}{c}{ Motivos } & Frequência & Porcentagem & $\begin{array}{c}\text { Porcentagem } \\
\text { válida }\end{array}$ & $\begin{array}{c}\text { Porcentagem } \\
\text { acumulativa }\end{array}$ \\
$\begin{array}{l}\text { Outros Natureza teórica, não aplicável. } \\
\text { Não expôs motivos da aplicabilidade à }\end{array}$ & 24 & 48,0 & 64,9 & 64,9 \\
chefia. & 5 & 10,0 & 13,5 & 78,4 \\
$\begin{array}{l}\text { Diagnóstico de situação, não aplicável. } \\
\text { Expôs as vantagens ao chefe, mas o }\end{array}$ & 3 & 6,0 & 8,1 & 86,5 \\
mesmo não se interessou. & 2 & 4,0 & 5,4 & 91,9 \\
Tentou expor as vantagens da & 1 & 2,0 & 2,7 & 94,6 \\
aplicabilidade ao chefe sem sucesso. & 1 & 2,0 & 2,7 & 97,3 \\
Falta de apoio dos colegas. & 1 & 2,0 & 2,7 & 100,0 \\
Natureza teórica, não aplicável. & 37 & 74,0 & 100,0 & \\
Total & 13 & 26,0 & & \\
Ausente Sistema & 50 & 100,0 & & \\
Total & & & & \\
\hline
\end{tabular}

Fonte: Dados da pesquisa (2018)

No que diz respeito aos motivos da não aplicação ou aplicação em parte do conhecimento produzido nas pesquisas (conforme a Tabela 6), o que chamou a atenção foi o quantitativo de TAEs (24 - 48\%) que declararam "Outros", e entre suas justificativas estão as que se seguem:

a. O processo ainda está em andamento,

b. Não vi interesse da UFPE na aplicação,

c. A temática foi diversa da minha área,

d. A temática estudada foi em local fora da UFPE,

e. Demanda de orçamento financeiro,

f. O setor ficou inativo,

g. Será aplicado futuramente,

h. Para o conhecimento ser aplicado precisaria de uma mudança de cultura.

Jones e Leonard (2009) apontam que são necessárias algumas características relevantes para criar um ambiente favorável de transferência do conhecimento: cultura de incentivo à inovação, cultura colaborativa, suporte da administração superior, equipe formal envolvida e comprometida e comunicação. Pelo que se lê nas respostas dos TAEs, essas questões não haviam sido discutidas no âmbito da universidade.

Continuando com a análise, os resultados na Tabela 7 apontam que a grande maioria $(88 \%)$ gostaria de aplicar os conhecimentos nas suas atividades quotidianas (onde a questão 
foi: Você gostaria que o conhecimento adquirido com a dissertação fosse aplicado em sua prática profissional?).

Tabela 7 - Desejo de aplicar os conhecimentos produzidos na pesquisa na prática profissional

\begin{tabular}{lccc}
\hline \multicolumn{1}{c}{ Desejo de aplicar os conhecimentos } & Frequência & Porcentagem & $\begin{array}{c}\text { Porcentagem } \\
\text { acumulativa }\end{array}$ \\
Gostaria & 44 & 88,0 & 88,0 \\
Não Gostaria & 4 & 8,0 & 96,0 \\
Indiferente & 2 & 4,0 & 100,0 \\
Total & 50 & 100,0 & \\
\hline
\end{tabular}

Fonte: Dados da pesquisa (2018)

Interessante observar que, no que diz respeito à relação entre o conhecimento aplicado na prática administrativa da UFPE (ver Tabela 5) e o desejo de aplicar o conhecimento (ver Tabela 7), nota-se que, enquanto 23 TAEs declararam que o conhecimento não foi aplicado, 19 gostariam de aplicar os conhecimentos adquiridos nas dissertações (Tabela 8).

Tabela 8 - Aplicação do conhecimento e o desejo aplicação

\begin{tabular}{|c|c|c|c|c|c|}
\hline \multicolumn{2}{|c|}{ Aplicação do conhecimento } & \multicolumn{4}{|c|}{ Desejo de aplicar o conhecimento na prática profissional } \\
\hline & & Gostaria & Indiferente & Não gostaria & Total \\
\hline \multirow{3}{*}{$\begin{array}{l}\text { O conhecimento foi } \\
\text { aplicado na prática } \\
\text { administrativa da UFPE }\end{array}$} & Não & 19 & 1 & 3 & 23 \\
\hline & Em parte & 13 & 1 & 0 & 14 \\
\hline & Sim & 12 & 0 & 1 & 13 \\
\hline Total & & 44 & 2 & 4 & 50 \\
\hline
\end{tabular}

Fonte: Dados da pesquisa (2018)

Nesse aspecto, cabe destacar importantes peculiaridades que as organizações deveriam atender e que deveriam estar presentes, antes, durante e depois de uma iniciativa de qualificação, visando à absorção, transferência e aplicação do conhecimento (JONES; LEONARD,2009; BHATT, 2001). Na concepção desses autores, é importante que a organização comunique a necessidade e o valor de uma cultura colaborativa aos seus servidores. $O$ suporte da administração superior é considerável, essencial. Embora outros líderes iniciem o processo, os funcionários precisam ver que a alta administração apoia o esforço.

Isso compreende, segundo Jones e Leonard (2009), falar sobre a iniciativa para gerentes intermediários, uma vez que estes serão vistos e ouvidos pelas demais chefias e funcionários. Esses gerentes precisam ser pessoas confiáveis e respeitados pelos funcionários, caso contrário, os mesmos poderão proteger seus conhecimentos.

Segundo uma das Pró-Reitoras, há interesse por parte da PROGEPE em incentivar a aplicação dos conhecimentos produzidos nas pesquisas, inclusive inserindo no edital do processo seletivo proposições de temáticas e intervenções sobre o próprio trabalho dos TAEs na universidade, desde que alinhadas às linhas de pesquisas dos programas.

Uma questão do questionário aplicado aos TAEs, procurou saber: De quem ou de que setor da UFPE, e em que fase de seu envolvimento com o mestrado, o servidor recebeu algum apoio ou orientação para aplicar os conhecimentos construídos em sua dissertação. Podendo, nessa questão, eleger mais de uma alternativa, o que justifica o valor total acima dos 50 respondentes. A Tabela 9 apresenta as respostas. 
Tabela 9 - Apoio ou orientações recebidas durante o processo de pesquisa

De quem ou de que setor da UFPE recebeu algum apoio/orientação para aplicar os conhecimentos construídos em sua dissertação

\begin{tabular}{lccc}
$\begin{array}{c}\text { De quem ou de que setor da UFPE recebeu algum } \\
\text { apoio/orientação para aplicar os conhecimentos } \\
\text { construídos em sua dissertação }\end{array}$ & $\begin{array}{c}\text { No de } \\
\text { Servidores }\end{array}$ & Quantitativo & $\%$ \\
Do orientador & 50 & 35 & $70 \%$ \\
De colegas & 50 & 28 & $56 \%$ \\
Da chefia imediata & 50 & 23 & $46 \%$ \\
Da PROGEPE & 50 & 10 & $20 \%$ \\
\hline
\end{tabular}

Fonte: Dados da pesquisa (2018)

O que se observa é que o próprio orientador, talvez pelo seu envolvimento com o trabalho, foi o ator que mais apoiou e incentivou a aplicação do resultado da pesquisa. Esse resultado corrobora com a Tabela 8 , pois demonstra que os pesquisadores acreditavam nos resultados de suas pesquisas e conseguiam vislumbrar os resultados organizacionais com sua aplicação. Por outro lado, esse resultado recomenda à PROGEPE buscar apoio dos próprios orientadores dos programas de mestrado profissional nos esforços de transferência e aplicação dos conhecimentos produzidos nas pesquisas.

A Tabela 10 traduz as respostas da questão: Você gostaria de discutir com a PROGEPE ou com sua chefia, a temática da dissertação antes da realização do mestrado visando uma possível aplicação? Embora os TAEs não tenham recebido apoio desejado da gestão, 44 (88\%) deles declararam que gostariam de trocar ideias sobre sua temática de pesquisa com lideranças da UFPE.

Tabela 10 - Disposição para debater o tema de pesquisa

\begin{tabular}{lccc}
\multicolumn{1}{c}{ Disposição para debater o tema } & Frequência & Porcentagem & $\begin{array}{c}\text { Porcentagem } \\
\text { cumulativa }\end{array}$ \\
Gostaria & 44 & 88,0 & 88,0 \\
Não Gostaria & 4 & 8,0 & 96,0 \\
Indiferente & 2 & 4,0 & 100,0 \\
Totais & 50 & 100,0 & \\
\hline
\end{tabular}

Fonte: Dados da pesquisa (2018)

E, mais importante, é observar a relação entre esse desejo dos TAEs de discutir a temática da dissertação antes da realização do mestrado, visando a uma possível aplicação, e a solicitação da chefia referente à contribuição da pesquisa (ver Tabela 11). Do total de 50 respondentes, 45 declararam que a chefia não solicitou que o trabalho trouxesse alguma melhoria para o setor. Todavia, 29 TAEs gostariam de discutir, antes, a temática com a chefia ou com a PROGEPE.

Trazendo ao debate a potenciação das capacidades dinâmicas, desenvolvidas por meio do conhecimento acumulado ao longo dos anos (TEECE et al., 1997; TEECE, 2007; CEPEDACARRION et al., 2017), a criação de conhecimento não significa somente desenvolver produtos, processos e serviços inovadores. Uma organização pode reconfigurar e recombinar os conhecimentos existentes, concentrando-se em suas capacidades e limitando suas deficiências.

Ao inserir seus servidores técnicos administrativos nos mestrados profissionais, a universidade está fortalecendo suas capacidades de pesquisa e desenvolvimento e empregando novas tecnologias na área técnico-administrativa. Essa iniciativa pode transformar as bases de conhecimento de gestão da universidade, incluindo novos conhecimentos de fora, ou ainda criar as condições para organizar e interpretar 
conhecimentos existentes dentro da organização sob uma nova perspectiva. Pelo que indicam as declarações dos TAEs, o desejo de colaborar com a universidade estava latente, faltava apenas ação gerencial.

Por outro lado, a iniciativa de inserir os TAEs nos mestrados profissionais já é um fomento ao desenvolvimento de novas práticas de gestão em toda a sua amplitude, para beneficiar a instituição e a sociedade, embora o que se concluiu nas entrevistas com as duas Pró-Reitoras da PROGEPE é que não houve, por parte da universidade, uma política de monitoramento e avaliação dos TAEs participantes dos cursos de mestrado profissional antes, durante e após todo o processo.

Tabela 11 - Disposição para debater o tema de pesquisa com lideranças da UFPE e solicitação da chefia referente à contribuição da pesquisa

\begin{tabular}{lccccc}
\hline & & \multicolumn{2}{c}{ Desejo de discutir antes a temática com a chefia ou PROGEPE } \\
& Gostaria & Indiferente & Não gostaria & Total \\
$\begin{array}{l}\text { Chefe solicitou que o } \\
\text { trabalho trouxesse }\end{array}$ & Não & 29 & 6 & 10 & 45 \\
melhoria & Sim & 3 & 2 & 0 & 5 \\
Total & & 32 & 8 & 10 & 50 \\
\hline
\end{tabular}

Fonte: Dados da pesquisa (2018)

Em relação à questão: Você gostaria de desenvolver uma temática na sua dissertação que fosse de interesse da UFPE e que tivesse, portanto, grande potencial de aplicabilidade na instituição? A Tabela 12 mostra que 46 (92\%) TAEs gostariam de desenvolver uma pesquisa com potencial de aplicação na universidade.

Tabela 12 - Desejo de desenvolver um tema de pesquisa com potencial de aplicação na UFPE

\begin{tabular}{lccc} 
Tabela 12 - Desejo de desenvolver um tema de pesquisa com potencial de aplicação na UFPE \\
\hline \multicolumn{1}{c}{ Desejo de desenvolver um tema } & Frequência & Porcentagem & $\begin{array}{c}\text { Porcentagem } \\
\text { acumulativa }\end{array}$ \\
Gostaria & 46 & 92,0 & 92,0 \\
Não Gostaria & 3 & 6,0 & 98,0 \\
Indiferente & 1 & 2,0 & 100,0 \\
Total & 50 & 100,0 & \\
\hline
\end{tabular}

Fonte: Fonte: Dados da pesquisa (2018)

A pergunta a seguir teve por objetivo estimular os TAEs a refletir sobre os resultados de suas pesquisas: Qual o potencial de aplicabilidade dos conhecimentos construídos em sua dissertação no âmbito da UFPE? Mesmo com a baixa taxa de aplicação do conhecimento revelada na Tabela 5, os TAEs acreditavam (ver Tabela 13) que esses conhecimentos teriam um grau considerável de aplicabilidade, com 23 (46\%); ou grande potencialidade, no caso, 20 (40\%); e outros cinco (10\%), médio grau de aplicabilidade.

Tabela 13 - Potencial de aplicabilidade do conhecimento produzido na pesquisa

\begin{tabular}{lccc}
\hline Potencial de aplicabilidade & Frequência & Porcentagem & $\begin{array}{c}\text { Porcentagem } \\
\text { cumulativa }\end{array}$ \\
Considerável & 23 & 46,0 & 46,0 \\
Grande & 20 & 40,0 & 86,0 \\
Médio & 5 & 10,0 & 96,0 \\
Pequeno & 1 & 2,0 & 98,0 \\
Nenhum & 1 & 2,0 & 100,0 \\
& & 100,0 & \\
\hline
\end{tabular}

Fonte: Dados da pesquisa (2018) 
As questões acima e suas respostas correspondentes circunscrevem a pesquisa como um processo de produção de conhecimento que contribui na interpretação da realidade vivida pelos TAEs. Minayo (2002) entende por pesquisa a atividade básica da ciência na sua indagação e construção da realidade, "nada pode ser intelectualmente um problema, se não tiver sido, também, um problema da vida prática" (MINAYO, 2002, p. 17). A função da pesquisa, nesta perspectiva, é a "prática social de conhecimento" (SANTOS, 1989), conferindoIhe como objetivo último o conhecimento para a vida social. Se o conhecimento instrumentaliza o ser humano para pensar e agir mais conscientemente sobre o mundo, ou sobre sua prática social, pesquisar é produzir conhecimento para a ação.

\section{CONSIDERAÇÕES FINAIS}

Esta pesquisa investigou o grau de aplicabilidade dos conhecimentos adquiridos na realização das dissertações de mestrado para contribuir com demandas específicas da prática profissional dos concluintes dos cursos de mestrado profissional da UFPE.

Se 79 dissertações investigaram temas cujo locus de análise era a própria universidade, conclui-se que a inserção social dos mestrados profissionais é visivelmente profissional, além de também ser científica. Carece, no entanto, de uma política de incentivo de transferência e aplicação do conhecimento produzido no âmbito organizacional.

Ademais, este estudo apontou que os TAEs demonstraram interesse em aplicar os conhecimentos por eles produzidos e, além disso, os mesmos acreditavam no potencial de aplicação dos conhecimentos gerados a partir de suas pesquisas. A aplicação dos conhecimentos produzidos nas dissertações, a partir de pesquisas realizadas diretamente com sua área de atuação ou em áreas estratégicas definidas pela própria UFPE, poderiam concretizar o debate naquilo que se concebe como uso social da ciência.

Se realmente se quer servidores públicos qualificados, capazes de pensar e contribuir efetivamente para o alcance dos objetivos organizacionais, importa reconhecê-los como profissionais que, a partir de seus domínios, estão aptos a selecionar as técnicas ou os modelos de gestão mais adequados ao tipo de problema que estão resolvendo.

Para finalizar, há de se considerar as limitações desta pesquisa. Aplicar ou não aplicar os conhecimentos adquiridos no mestrado profissional na prática profissional, não são se trata apenas de uma decisão gerencial, existem outras variáveis que influenciam o grau de aplicabilidade dos conhecimentos adquiridos, as quais não foram consideradas pelos autores deste trabalho. Nessa perspectiva, sugere-se investir em futuras pesquisas para investigar quais são as outras variáveis que influenciam na aplicabilidade dos conhecimentos adquiridos nos mestrados profissionais. Ademais, investigar como os TAEs, eles mesmos, poderiam encontrar meios e respostas, juntamente com as universidades, para aplicarem seus conhecimentos na prática organizacional. Futuras pesquisas também poderiam analisar o grau de institucionalização das dissertações que se tornaram produtos tecnológicos e/ou artigos científicos, seja em congressos ou em periódicos. Além disso, poderia se replicar o mesmo tipo de pesquisa em outras universidades.

\section{REFERÊNCIAS}

ANDREEVA, T.; CHAIKA, V. Dynamic capabilities: what they need to be dynamic? Working Paper, 10 (E) St. Petersburg State University, São Petersburgo, 2006. 
BATISTA, F. F. Modelo de gestão do conhecimento para a administração pública brasileira: como implementar a gestão do conhecimento para produzir resultados em benefício do cidadão. Brasília: Ipea, 2012.

BOURDIEU, P. Os usos sociais da ciência: por uma sociologia clínica do campo científico. São Paulo: UNESP, 2003.

BRASIL. Lei no 11.091, de 12 de janeiro de 2005. Diário Oficial [da] República Federativa do Brasil, Poder Executivo, Brasília, DF, 13 jan. 2005, Seção 1, p. 1.

BRASIL. Lei no 12.772, de 28 de dezembro de 2012. Diário Oficial [da] República Federativa do Brasil, Poder Executivo, Brasília, DF, 31 dez. 2012, Seção 1, p. 1.

BRASIL. Decreto no 5.707, de 23 de fevereiro de 2006. Diário Oficial [da] República Federativa do Brasil, Poder Executivo, Brasília, DF, 24 fev. 2006, Seção 1, p. 3.

BRASIL. Decreto no 5.825, de 29 de junho de 2006. Diário Oficial [da] República Federativa do Brasil, Poder Executivo, Brasília, DF, 30 jun. 2006, Seção 1, p. 64.

BHATT, G. D. Knowledge management in organizations: examining the interaction between technologies, techniques, and people. Journal of Knowledge Management, v. 5, n. 1, p. 68-75, 2001.

CAPES. Portaria no 080, de 16 de dezembro de 1998. Diário Oficial [da] República Federativa do Brasil, Poder Executivo, Brasília, DF, 11 jan. 1999, Seção 1, p. 14.

CAPES. Portaria Normativa no 17, de 28 de dezembro de 2009. Diário Oficial [da] República Federativa do Brasil, Poder Executivo, Brasília, DF, 29 dez. 2009, Seção 1, p. 20.

CEPEDA-CARRION, I.; MARTELO-LANDROGUEZA, S.; LEAL-RODRÍGUEZ, A. L.; LEAL-MILLÁN, A. Critical processes of knowledge management: An approach toward the creation of customer value. European Research on Management and Business Economics, v. 23, p. 1-7, 2017.

COHEN, W. M.; LEVINTHAL, D. A. Absorptive capacity: A new perspective on learning and innovation. Administrative Science Quarterly, v. 35, n. 1, p.128-152, 1990.

COORDENAÇÃO DE APERFEIÇOAMENTO DE PESSOAL DE NÍVEL SUPERIOR CAPES. Portaria no 080, de 16 de dezembro de 1998. Diário Oficial [da] República Federativa do Brasil, Poder Executivo, Brasília, DF, 11 jan. 1999, Seção 1, p. 14.

COORDENAÇÃO DE APERFEIÇOAMENTO DE PESSOAL DE NÍVEL SUPERIOR CAPES. Portaria Normativa no 17, de 28 de dezembro de 2009. Diário Oficial [da] República Federativa do Brasil, Poder Executivo, Brasília, DF, 29 dez. 2009, Seção 1, p. 20.

GARCIA, J.C. R.; SILVA, E. M. Nuanças e estratégias que circundam o conhecimento tácito. Navus, Florianópolis, SC, v. 5, n. 3, p. 06-21, jul./set. 2015.

GARCÍA, M. Ú.; CORTÉS, E.C.; MARCO-LAJARA, B.M.; ZARAGOZA - SÁEZ, P. Strategy, training and performance fit. International Journal of Hospitality Management, v. 24, p. 100-116, 2014.

Perspectivas em Gestão \& Conhecimento, João Pessoa, v. 8, n. 3, p. 179-191, set./dez. 2018. 
HEIDEN, P. van der.; POHL, C.; MANSOR, S. B.; GENDEREN, J. van. The role of education and training in absorptive capacity of international technology transfer in the aerospace sector. Progress in Aerospace Science, v.76, p. 42-54, 2015.

KANG, M.; HAU, Y. S. Multi-level analysis of knowledge transfer: Aknowledge recipient's perspective. Journal of Knowledge Management, v.18, n. 4, p. 758-776, 2014.

KONTOGHIORGHES, C. Reconceptualizing the learning transfer conceptual framework: Empirical validation of a new systemic model. International Journal of Training and Development, v.8, p.210-221, 2004.

JONES K.; LEONARD, L. N. K. W. R. From tacit knowledge to organizational knowledge for successful. KING, K. M. (ed.), Knowledge management and organizational learning. Annals of Information Systems, 4, 2009.

LAI, M.; PENG, S. BAO. Q. Technology spillovers, absorptive capacity and economic growth. China Econ.Rev.v.17, n. 3, p. 300-320, 2006.

LIM, K. Themany faces of absorptive capacity: spill overs of copper interconnect technology for semiconductor chips, Ind. Corp. Change, v.18, n. 6, p. 1249-1284, 2009.

MARTINS, G. de A.; THEÓPHILO, C.R. Metodologia da investigação científica para Ciências Sociais Aplicadas. 2. ed. São Paulo: Atlas, 2009.

MARTELETO.R.M. Conhecimentos e conhecedores: apontamentos sobre a ciência, os pesquisadores e seu papel social. In: MARTELETO, R. M.; STOTZ, E. N. (Org.). Informação, saúde e redes sociais: diálogos de conhecimentos nas comunidades da Maré. Rio de Janeiro: Editora FIOCRUZ, 2009.

MUROVEC, N. PRODAN, I. Absorptive capacity, its determinants, and influence on innovation output: Cross-cultural validation of the structural model. Technovation, v. 29 , n. 12 , p. 859872, 2009.

NEDJAT, S.; GHOLAMI, J.; YAZDIZADEH, B.; NEDJAT, S.; MALEKI, K.; MAJDZADEH, R. Research's Practice and Barriers of Knowledge Translation in Iran. Iran J Public Health. Jul; v. 43, n. 7, p. 968-980, 2014.

NONAKA, I.; TAKEUCHI, H. Criação de conhecimento na empresa: como as empresas japonesas geram a dinâmica da inovação. Tradução de Ana Beatriz Rodrigues e Priscila Martins Celeste. 12. ed. Rio de Janeiro: Elsevier, 1997.

RIBEIRO, C.R. A universidade como disputa da reprodução social: contribuição ao debate sobre os mestrados profissionais. RBPG, Brasília, v. 7, n. 14, p. 433 - 450, dez. 2010.

SALAS, E.; TANNENBAUM, S.I.; KRAIGER, K.; SMITH-JENTSCH, K. A. The science of training and development in organizations: what matters in practice. Psychological Science, v.13, n. 2, p. 74-101, 2012.

SITZMANN, T.; BROWN, K. G.; ELY, K.; KRAIGER, K. Motivation to learn in a military training curriculum: A longitudinal investigation. Military Psychology, v.21, p. 534-551, 2009. 
TEECE, D. J.; PISANO, G.; SHUEN, A. Dynamic capabilities and strategic management. Strategic Management Journal, v.18, n. 7, p.509-533, 1997.

TEECE, D. J. Explicating dynamic capabilities: the nature and microfoundations of (sustainable) enterprise performance. Strategic Management Journal, v. 28, p. 1319-1350, 2007.

UNIVERSIDADE FEDERAL DE PERNAMBUCO. Resolução no 9, de 19 de dezembro de 2006. Recife: UFPE, 2006.

VERGARA, S. C. Projetos e relatórios de pesquisa em administração. 3. ed. São Paulo: Atlas, 2000.

VOLPATO, G. Ciência: da filosofia à publicação. 6. ed. São Paulo: Cultura Acadêmica, 2013. 